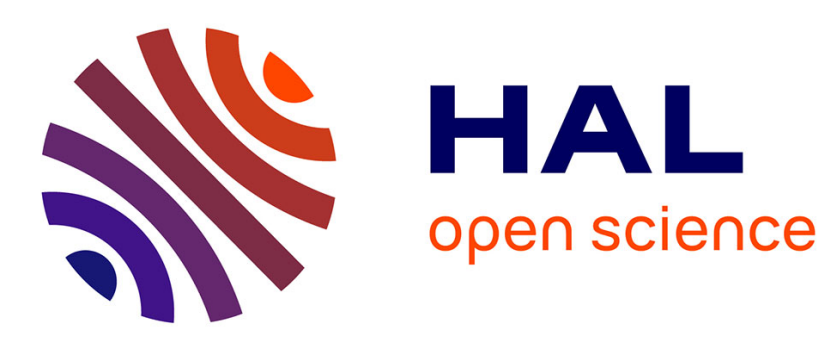

\title{
Thermal Cycling Effect on the Premartensitic and Martensitic Transition in a Ti Rich NiTi Alloy
}

V. Pelosin, F. Deborde, A. Rivière

\section{To cite this version:}

V. Pelosin, F. Deborde, A. Rivière. Thermal Cycling Effect on the Premartensitic and Martensitic Transition in a Ti Rich NiTi Alloy. Journal de Physique IV Proceedings, 1996, 06 (C8), pp.C8-429C8-432. 10.1051/jp4:1996893 . jpa-00254704

\section{HAL Id: jpa-00254704 https://hal.science/jpa-00254704}

Submitted on 1 Jan 1996

HAL is a multi-disciplinary open access archive for the deposit and dissemination of scientific research documents, whether they are published or not. The documents may come from teaching and research institutions in France or abroad, or from public or private research centers.
L'archive ouverte pluridisciplinaire HAL, est destinée au dépôt et à la diffusion de documents scientifiques de niveau recherche, publiés ou non, émanant des établissements d'enseignement et de recherche français ou étrangers, des laboratoires publics ou privés. 


\title{
Thermal Cycling Effect on the Premartensitic and Martensitic Transition in a Ti Rich NiTi Alloy
}

\author{
V. Pelosin, F. Deborde and A. Rivière \\ Laboratoire de Mécanique et de Physique des Matériaux, URA 863 du CNRS, ENSMA, Site du \\ Futuroscope, BP. 109, 86960 Futuroscope cedex, France
}

\begin{abstract}
The study was carried on a Ti-rich NiTi shape memory alloy. The electrical resistance and the elastic modulus were determined versus temperature. The aim of this work is to study the thermal cycling effect on the transformation features as the temperatures or the phase succession as well as the structural modifications. The major results of this work concern the R-phase occurrence and its evolution. We have shown that the premartensitic phase could exist in a narrow range of temperature on cooling and is revealed only after a few cycles. In fact, its presence and stability is directly linked to the diminishing of Ms. The main condition for the austenite to be transform in a rhombohedral structure is that Ms becomes low enough to be below Tr. Interrupted cooling runs also show that contrarily to the austenite-martensite transition, the austenite-R-phase transition doesn't exhibit any hysteretic behaviour.
\end{abstract}

\section{INTRODUCTION}

NiTi based alloys are among the shape memory alloys the most technologically used, therefore one of the most studied. Up to now, many investigations have been focused on equiatomic NiTi $[1,2,3]$ or Ni rich alloys $[4,5,6]$. Few studies are related to the thermomechanical behavior of a Ti rich NiTi $[7,8]$. The purpose of the present work is a study of the premartensitic (R-phase) and the martensitic transition occurring in a $\mathrm{Ti}-49.6 \% \mathrm{Ni}$ initially solution treated. We will examine with great attention the effect of thermal cycling on the transition sequences.

\section{EXPERIMENTAL PROCEDURE}

The alloy composition was determined by chemical analysis to be Ti- $49.6 \% \mathrm{Ni}$. The sample with typical dimensions of $5 \mathrm{~mm} \times 30 \mathrm{~mm} \times 0.2 \mathrm{~mm}$ was solution treated in vacuum furnace $(\mathrm{P}<10-6$ torr) for ten hours at $800^{\circ} \mathrm{C}$ then furnace cooling (approximately $4^{\circ} \mathrm{C} / \mathrm{min}$ ).

Electrical resistance was measured as a function of temperature using a conventional four-probe method. Elastic modulus and internal friction measurements were performed on a vibrating reed device by determining the natural frequency of the strip and calculating the free decay of the amplitude vibration. In the following, for convenience, we have focused our study on the cooling treatments.

\section{RESULTS}

\subsection{Resistivity}

The sample has been submitted to thirty thermal cycles. The intrinsic values have been normalized to that measured at $20^{\circ} \mathrm{C}$ for the first cycle. The resistivity measurements obtained on cooling are depicted on figure 1 . The most striking features are in one hand the depressing of the 
temperature transition, in the other hand the occurrence and above all the development of a net maximum of resistivity after the sixth thermal cycle. More precisely the cooling curves corresponding to $N=1,2,4$ and 6 are characterized by three different steps: first resistivity decrease linearly on the high temperature phase (austenite) until Ms, then the resistivity falls sharply during the transition. Finally, the sample is in a martensitic phase, its resistivity declined linearly for $\mathbf{T}<\mathrm{Mf}$.

Concerning the cycles $\mathrm{N}=8,11,20,25$ and 30 the situation is quite different. Indeed, even if both the evolution in the austenitic and the martensitic phases stays similar, a premartensitic stage is now revealed by the increasing of the resistivity between a constant temperature $\left(\approx 81^{\circ} \mathrm{C}\right)$ and $\mathrm{Ms}$ (reaching a maximum at approximatively $62^{\circ} \mathrm{C}$ ). Then, the classical martensitic transition occurred as the resistivity fall sharply until Mf. Assuming the fact that $\operatorname{Tr}$ (beginning of the distortion of the austenite) is not affected by thermal cycling and that the presence of the R-phase is usually detected by a increasing of the resistivity $[7,8,9]$ one could associated the premartensitic present effect to the occurrence of the R-phase and $\operatorname{Tr}$ could be considered as the beginning temperature of this transition, observed at approximately $81^{\circ} \mathrm{C}$. One could notice that the cycle $\mathrm{N}=8$ is a borderline case as $\mathrm{Ms}$ and $\mathrm{Tr}$ are very close (the proportion of $\mathrm{R}$-phase is not sufficient to make the resistivity increase).

The decreasing of the temperature $\mathrm{Ms}$ and $\mathrm{Mf}$ is indicated with arrows on figure 1 . This effect is quite well explained by the fact that the thermomechanical solicitation due to the thermal cycling introduces dislocations and thus a stress field which depressed all the temperature transitions. This tendency has been observed by other authors in Ti rich NiTi: [7] for Ti-50.2\%, or [10] for Ti50,5\%at and $\mathrm{Ti} 51 \%$ at.

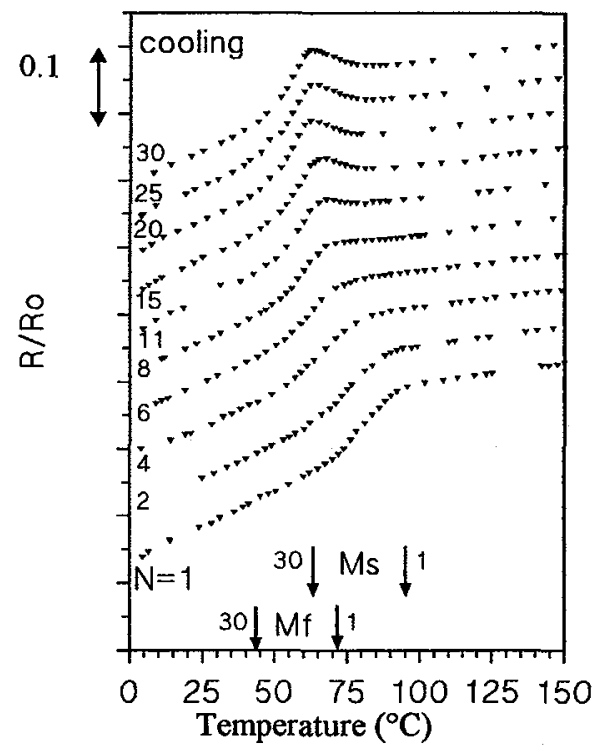

Figures 1. Effect of thermal cycling on the electrical resistance versus temperature on cooling. The arrows indicate the evolution of Ms and Mf between the first and the 30 th cycle.

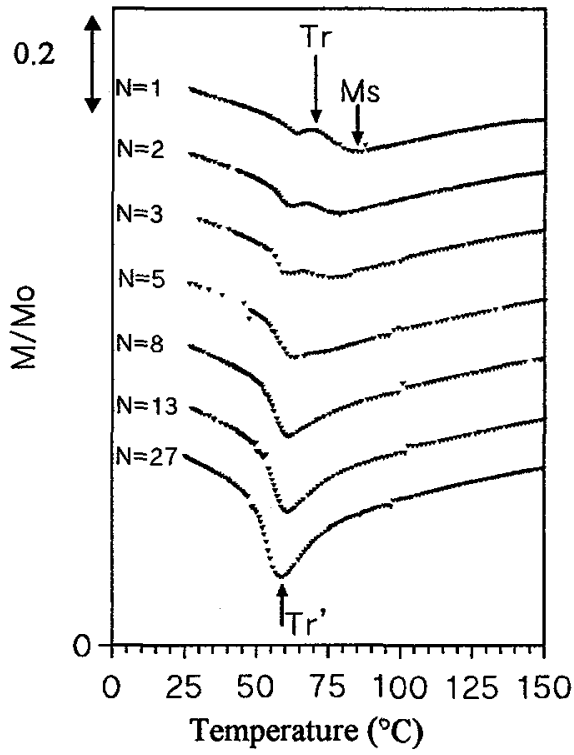

Figure 2. Effect of thermal cycling on the modulus evolution (also on cooling). Ms of the first cycle as well as the position of $\mathrm{Tr}$ and ' $\mathrm{Tr}$ ' are reported.

\subsection{Flexural modulus}

The second step of our work deals with the elastic flexural modulus behavior as a function of temperature and thermal cycling. Figure 2 shows the modulus evolution (normalized to the $20^{\circ} \mathrm{C}$ measurement obtained during the first cycle) on cooling. First, it could be observed a modulus deep occurring at the same temperature, Tr', for all thermal cycles. Secondly, the amplitude of the 
modulus softening is growing with the number of cycles. The interpretation of this effect needs some detailed explanations. For the first cycles, $N=1,(2$ and 3$) \mathrm{Ms}$ could be considered as the first value on cooling where the modulus increases, then the trend changes for the temperature called $\mathrm{Tr}$ and the modulus falls again until $\mathrm{Tr}^{\prime}$ where it finally rises up for the end of the cooling. This tendency is not reproduced for $\mathrm{N}>5$, where both $\mathrm{Ms}$ and $\mathrm{Tr}$ could not be detected anymore as the modulus decreases from the high temperature phase until $\mathrm{Tr}^{\prime}$. It is now well established that the occurrence of the Rphase is closely related with an elastic softening $[1,10,11]$, so we can speculate that $\operatorname{Tr}$ is the temperature where the austenite is distorted and begins to transform in the R-phase. On the following cycles one can notice that $\mathrm{Ms}$ is lowered so that $\operatorname{Tr}$ become less and less discernible. Indeed, on the cooling curves, the modulus is only increased by the presence of martensite, then when Ms becomes much lower than $\operatorname{Tr}(\mathrm{N}>6)$, the NiTi structure on each part of $\mathrm{Tr}$ is completely austenitic for $T>\operatorname{Tr}$ and a mix of austenite and $R$-phase for $T<\operatorname{Tr}$. In the two cases the modulus is decreased in such a way that $\mathrm{Tr}$ could not be clearly detected.

The other characteristic temperature, $\mathrm{Tr}^{\prime}$, has been localized around $62^{\circ} \mathrm{C}$. The fact that $\mathrm{Tr}^{\prime}$ doesn't depend on thermal cycling could indicate that it is closely linked to the R-phase. Assuming that the $\mathbf{R}$-phase transition is not instantaneous, but just like the martensite transition extends between two temperatures, it would be correct to assume that $\mathrm{Tr}^{\prime}$ corresponds to the end of R-phase transformation. All these results confirm that the R-phase could be present ever since the first cycle (but not revealed by our measurements). Its apparent development is not directly due to the thermal cycling, that is to say a structural evolution, but only to the fact that Ms is depressed. It is also shown that $\mathrm{Tr}$ and $\mathrm{Tr}$ ' remain constant. All this goes to confirm that the R-phase is insensitive to thermal cycling.

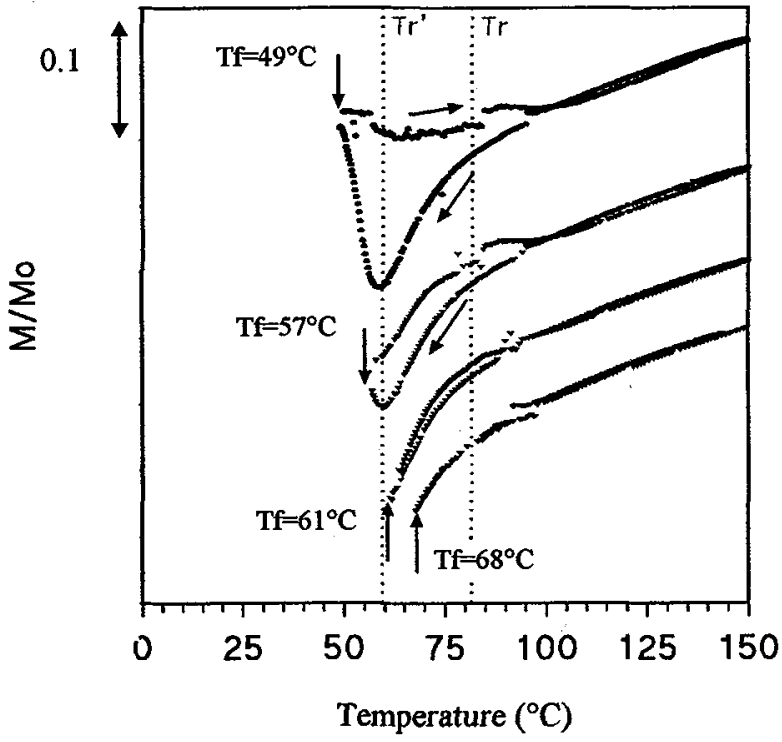

Figure 3. Modulus evolution measured during interrupted thermal cycles performed between $150^{\circ} \mathrm{C}$ and $68^{\circ} \mathrm{C}$, $61^{\circ} \mathrm{C}, 57^{\circ} \mathrm{C}$ and $49^{\circ} \mathrm{C}$. The sample has been thermally cycled more than thirty times.

Interesting information is also given by interrupted thermal cycles on cooling, where the final temperature, $\mathrm{Tf}$, has been fixed to $48^{\circ} \mathrm{C}, 57^{\circ} \mathrm{C}, 61^{\circ} \mathrm{C}$ and $68^{\circ} \mathrm{C}$, instead of room temperature. Tf has been chosen to be characteristic of the main steps of the transformations. This study has been done for $N>30$ in order to be sure that the complete cycle is stabilized. Figure 3 illustrates the results of such experiments. On the cycle interrupted at $68^{\circ} \mathrm{C}$, where the present phases are $A$ and $R$, one could noticed that the curve is perfectly reproducible on heating and on cooling. A first statement is that no 
hysteresis is detected with the occurrence or vanishing of the $\mathrm{R}$ phase. For a final cooling temperature of $61^{\circ} \mathrm{C}$, the modulus evolution is weakly different on cooling and on heating that could indicates, that a transformation with a hysteretic character just begins; these results show that Ms is close but higher than $61^{\circ} \mathrm{C}$. The previously described effects are more pronounced as the interrupted temperature is $57^{\circ} \mathrm{C}$. The amount of martensite formed is large enough to reveal an marked hysteretic behavior on modulus. The last cycle, interrupted at $49^{\circ} \mathrm{C}$ exhibits the same characteristics that a complete one. To sum up, we could underline the fact that no thermal hysteresis has been detected for the R-phase transition which is in good agreements with previous results performed on equiatomic NiTi [12] or on Ti $50.13 \%-\mathrm{Ni}$ [2]

\section{CONCLUDING REMARKS}

The two approaches followed, resistivity and modulus measurements, enable a detailed analysis of the successive phase transformations and their evolution with the temperature cycling occurring in a Ti- $49.6 \% \mathrm{Ni}$ alloys. Concerning the structural evolution, figure 4 gives a general view of the influence of thermal cycling on the different and succeeding steps of the transformations.

(Mf)

(Ms)

\begin{tabular}{|c|c|c|c|c|c|}
\hline $\mathbf{N}=\mathbf{1}$ & \multicolumn{2}{|c|}{$\mathbf{M}$} & $\mathbf{M}+\mathbf{A}+(\mathbf{R})$ & $\overline{\mathbf{A}+\mathbf{M}}$ & A \\
\hline $\mathbf{N}=\mathbf{3}$ & $\mathbf{M}$ & $\mathbf{M}+\mathbf{R}$ & $\mathbf{M}+\mathbf{R}+\mathbf{A}$ & $\mathbf{A}+\mathbf{M}$ & A \\
\hline$N=5-6$ & $\mathbf{M}$ & $\mathbf{M}+\mathbf{R}$ & $\mathbf{R}+\mathbf{A}+(\mathbf{M})$ & & A \\
\hline $\mathbf{N}=\mathbf{1 2}$ & $\overline{\mathbf{M}}$ & $\mathbf{M}+\mathbf{R}$ & $\overline{\mathbf{R}+\mathbf{A}}$ & & A \\
\hline $\mathbf{N}=\mathbf{3 0}$ & $\mathbf{M}$ & $M+R$ & $\overline{\mathbf{R}+\mathbf{A}}$ & & A \\
\hline
\end{tabular}

Figure 4. Transition evolution and present phases during cooling for various thermal cycles. When two or more phases coexist, the major one is the first mentioned. The parenthesis are used when the phases are supposed to be present in a minority. The double bars indicate the position of Ms and Mf.

\section{References}

[1] L. Jordan, M. Masse, J. Y. Collier and G. Bouquet, J. of Alloys and Comp., 211, (1994), 204207

[2] H. C. Ling and R. Kaplow, Metall. Trans. A, 12, (1981), 2101-2110

[3] L. Jordan, M. Chandrasekaran, M. Masse and G. Bouquet, J. de Phys IV, C2, 5, (1995), 489-494

[4] G. B. Stachowiak and P. G. McCornick, Acta Met., 36, (1988), 291-297

[5] M. Nishida and T. Honma, Scripta Met, 18, (1984), 1293-1298

[6] C. M. Wayman, MRS Internat. Meting on Adv. Mats, 1989, 9, 63-76

[7] S. Miyazaki, Y. Igo and K. Otsuka, Acta Metall,. 34, (1986), 2045-2051

[8] H. C. Ling and R. Kaplow, Metall. Trans. A, 11, (1980), 77-83

[9] L. Jordan, M. Masse, J. Y. Collier and G. Bouquet, J. de Phys. IV, C3, 4, (1994), 157-162

[10] H. C. Lin, S. K. Wu and J. C. Lin, Mat. Chem. and Phys., 37, (1994), 184-190

[11] S. K. Wu, H. C. Lin and T. S. Chou, Acta Metall. Mater., 38, (1990), 95-102

[12] G. D. Sandrock; A. J. Perkins and R.F. Hehemann, Metall. Trans., 2, (1971), 2769-2781 